\title{
As lições das coisas
}

\author{
Álamo Pimentel \\ Universidade Federal de Alagoas
}

\section{Resumo}

Os museus constituem espaços para o ensino de antropologia. A partir de um projeto didático de antropologia da educação em um museu de antropologia de uma universidade pública brasileira, emergem importantes significados para a experiência do estranhamento etnográfico com os objetos da exposição permanente. Mediante uma análise de relatórios de visita produzidos pelos estudantes, o autor apresenta os diferentes arranjos discursivos que compõem os acervos da exposição e revela, a partir das configurações de sentidos produzidas pelos estudantes, as principais lições das coisas que emergem desta experiência. Os resultados indicam que aspectos estéticos, ideológicos, diferentes marcas de gênero e sexualidade bem como a falta de conhecimento prévio se destacam como resultantes do estranhamento.

Palavras-chave: Antropologia da educação. Educação e museus. Ensino. 


\section{The Lessons of Things}

Museums are spaces for teaching anthropology. Based on an instructional project in anthropology of education at a museum of anthropology in a Brazilian public university, important meanings emerge for the experience of ethnographic estrangement towards objects from the permanent exhibition. Based on an analysis of visit reports produced by students, the author presents the different discursive arrangements that make up the collections of the exhibition, and reveals, based on the configurations of meanings produced by the students, the main "lessons of things" that emerge from this experience. The results indicate that aesthetic and ideological aspects, different marks of gender and sexuality, as well as the lack of prior knowledge are the main causes of estrangement.

Keywords: Anthropology of Education. Education and Museums. Teaching.

\section{Las lecciones de las cosas}

Los museos son espacios para la enseñanza de la antropología. A partir de un diseño instruccional de antropología de la educación en el Museo de Antropología de una universidad pública brasileña, emergen significados importantes para la experiencia del extrañamiento etnográfico con los objetos de la exposición permanente. A través de un análisis de los informes de las visitas realizadas por los alumnos, el autor presenta las diferentes modalidades discursivas que componen las colecciones y la exposición muestra, a partir de la configuración de significados producidos por los estudiantes, las principales lecciones de las cosas que surgen de esta experiencia. Los resultados indican que los aspectos estéticos, ideológicos, las diferentes marcas de género y la sexualidad, así como la falta de conocimientos previos se destacan como resultado del extrañamiento.

Palabras-clave: Antropología de la Educación. Educación y Museos. Educación. 


\section{Introdução}

Os museus antropológicos contribuem para a produção de práticas educativas nos processos de patrimonialização da cultura. Além de oferecerem, por meio dos seus acervos, importantes contribuições para o conhecimento de outras culturas, tais museus possibilitam o desenvolvimento de atividades voltadas para o ensino das práticas e dos saberes inerentes à antropologia.

A orientação pedagógica para a composição dos acervos dos museus antropológicos inscreve-se no início do século XX, momento inaugural da emergência da etnografia como prática de produção de conhecimento da antropologia ocidental. Em carta destinada ao presidente do Museu Americano de História Natural (datada de 29 de abril de 1905), Franz Boas destaca os seguintes aspectos referentes às funções educativas de um museu antropológico:

Parece-me que o objetivo principal de uma grande coleção antropológica é ilustrar todas as principais características da história da civilização humana [...] Assim, os principais pontos de vista que devem ser enfatizados são a relação do homem com a natureza, o desenvolvimento das técnicas de produção, as formas de costumes e crenças. Eles devem ser explicados levando em consideração as condições históricas de cada povo [...]. (Boas, 2004, p.357)

Além de destacar a relevância pedagógica dos espaços museais para a compreensão de outras civilizações, aquele que é considerado um dos pais da etnografia moderna enfatiza as dimensões temáticas com as quais a antropologia pode contribuir para disponibilização de saberes acerca de outras culturas. Em linhas gerais, as premissas indicadas por Franz Boas sugerem algumas faces de uma intencionalidade pedagógica presente na concepção dos museus antropológicos.

Apesar de as orientações teóricas (produzidas à luz dos debates antropológicos da épocal evidenciarem uma inclinação funcionalista' na abordagem da composição dos acervos na fixação de temas antropológicos, a partir do discurso de Boas, isto não esgota outras possibilidades de definição dos museus enquanto espaços marcados pela concepção antropológica de cultura e portadores de intenções pedagógicas, sobretudo quando remetemos as reflexões sobre museus a uma dimensão mais ampla e processual, qual seja a dimensão do patrimônio. A este respeito é importante lembrar que:

[...] A noção de cultura, tal como formulada pelos antropólogos culturais na tradição

1. Ver a este respeito o texto de introdução elaborado por George W. Stocking à obra citada. (Boas, 2004) 
de Franz Boas e de Bronislau Malinowski, trazendo em seu bojo as noções correlatas de diversidade, valorização da diferença, contextualização, relativização, emerge como solução adequada na luta contra o racismo, o etnocentrismo, o evolucionismo e a hierarquização dos povos numa história única e linear baseada em critérios de progresso e civilização [...]. (Abreu, 2007,p. 272)

$\mathrm{Na}$ perspectiva dos debates mais recentes sobre patrimônios e políticas patrimoniais no Brasil, o conceito antropológico de cultura inscreve importantes elementos que irão pautar as discussões sobre aspectos materiais e imateriais, locais e globais, memória individual e memória coletiva, bem como os conflitos que atravessam estes e outros aspectos conceituais e práticos que estão presentes nas reflexões sobre patrimônios culturais. É importante enfatizar, ainda segundo as provocações feitas por Regina Abreu (2007, p. 282), que, além dos aspectos conflituosos que estão presentes nos debates sobre patrimônios culturais le nos museus), há o risco iminente de naturalização de uma 'certa' concepção de cultura e diversidade; caso os antropólogos (e a antropologia em sentido mais amplo) não assumam aqueles que, segundo a autora, podem ser os seus papéis neste cenário: mediadores e articuladores das 'dimensões da humanidade' que estão presentes nos mais diferentes cenários dos patrimônios culturais.

As reflexões propostas por Regina Abreu inscrevem a ênfase epistemológica acerca da cultura no debate sobre as abordagens antropológicas dos processos de patrimonialização e indicam a relevância ética e política que thes são subjacentes, sobretudo no que diz respeito à crítica antropológica às visões mais etnocêntricas da cultura. Neste sentido a autora nos oferece uma orientação conceitual que possibilita extrapolar as limitações de uma visão mais funcional da cultura, ao tempo em que remete a noção de luta como processo que se instaura no âmbito das relações entre educação e cultura constitutivas dos processos de pratrimonialização. Ao lado das premissas lançadas por Franz Boas, os atos de mediar e articular indicam as outras faces da intencionalidade pedagógica que orienta as práticas educativas emergentes dos processos de patrimonialização da cultura a partir dos acervos museais.

Para a construção deste breve artigo, parto do pressuposto de que os museus antropológicos disponibilizam-nos lições das coisas ${ }^{2}$. Os objetos e as formas de organização que os expõem colocam em perspectiva arranjos discursivos sobre os quais a antropologia constitui a sua história enquanto área do conhecimento,

2. Pouco tempo após a elaboração deste artigo localizei o texto Lições das coisas: o enigma e os desafios da educação patrimonial de Maria de Lourdes Parreiras Horta (2005), apesar da aparente semelhança no uso do termo lições das coisas, utilizo uma abordagem diferente no tratamento do assunto, uma vez que não enfatizo nas minhas análises o desenvolvimento de uma educação patrimonial, mas destaco a relevância do ensino da antropologia educacional nos processos de patrimonialização da cultura. No entanto, considero importante destacar que a formulação original do termo "lições das coisas" pertence à autora mencionada anteriormente nesta nota. 
mas também enquanto prática de conhecimento na qual a cultura é a um só tempo conceito e processo de interação com a complexidade simbólica da nossa 'dimensão de humanidade'.

Neste sentido, tomo de empréstimo a noção de intencionalidade pedagógica a partir das indicações das 'funções educativas' propostas por Franz Boas, para compreendê-las como arranjos discursivos dos saberes antropológicos nos museus. Procuro ainda complementá-la com as noções de mediação e articulação destacadas anteriormente. Proponho a retomada da compreensão desta intencionalidade pedagógica' a partir da produção discursiva que atravessa os debates sobre museus e patrimônios culturais, apoiado nas posições teóricas afirmadas por Regina Abreu. Reconheço com esta autora que, ao colocar em destaque os papéis de mediador e articulador para os antropólogos (e educadores de uma maneira geral), contribuise para uma produção discursiva que amplia os saberes e práticas inerentes aos trabalhos com patrimônios culturais. É importante destacar ainda que esta composição entre a perspectiva lançada por Franz Boas e os desafios assinalados por Regina Abreu está pautada pelas orientações legadas por Carlos Rodrigues Brandão quando de suas reflexões sobre a educação como cultura. Para este autor, “o trabalho de transformar e significar o mundo é o mesmo que transforma e significa o homem [...] É uma ação socialmente necessária e motivada e a própria sociedade em que o homem se converte ser humano é parte da cultura [...]" (Brandão, 1986, p.23). Trabalhar a cultura por meio dos processos de mediação e articulação, bem como por meio do reconhecimento das funções educativas de um museu implica a produção social de sentidos que situa os indivíduos nas suas relações com os patrimônios culturais.

\section{Aprendizagens do estranhamento no museu}

No início do ano de 2013, elaborei um projeto didático intitulado ‘aprendizagens do estranhamento no Museu Afro-Brasileiro da UFBA - MAFRO-UFBA'. Participaram deste projeto estudantes matriculados no componente curricular de Antropologia da Educação do curso de pedagogia da Faculdade de Educação da UFBA. 0 meu propósito mais amplo era possibilitar aos estudantes uma compreensão do "conceito antropológico' de cultura mediante as coleções expostas no MAFRO. Cada estudante foi orientado a organizar um relatório da visita a partir de um roteiro previamente discutido em sala de aula no qual constavam as seguintes questões: qual objeto provocou o seu estranhamento? Por quê? Após a visita, com a entrega dos relatórios, percebi que, dos 21 estudantes, 11 deles haviam destacado estranhamentos referentes a objetos que eram relacionados ao Candomblé. Além disto, os relatórios 
apresentavam diferentes referências que remetem ao Candomblé. Considerei que tais respostas representavam um desafio interessante, a ênfase das exposições permanentes do MAFRO não está nas dimensões religiosas, mas nas dimensões históricas, étnicas e estéticas das relações identitárias entre diferentes nações africanas e a Bahia. No entanto a ênfase direta ou indireta ao 'Candomblé' como referência cultural $^{3}$ causadora de estranhamento indicava, aparentemente, a 'ressonância' de conflitos civilizacionais locais no que diz respeito às relações entre os estudantes e alguns dos objetos destacados em suas narrativas.

No ano de 2006, o MAFRO-UFBA produziu material impresso para orientar professores das escolas locais que visitam os seus acervos. 0 texto oficial do museu apresenta, em linhas gerais, as intencionalidades pedagógicas das suas exposições com o propósito de gerar ações educativas que possibilitem:

A construção de imagens da África alternativas aos estereótipos difundidos pela mídia e pela escola e divulgação de conhecimentos acerca da história dos africanos e afrodescendentes, com ênfase em dimensões essenciais de sua visão de mundo e de suas formas de organização social, evidenciadas nos objetos da exposição [...] 0 combate à intolerância religiosa e valorização da diversidade cultural [...] A realização de exercícios de leitura de objetos, provocando o olhar para seus elementos formais e fornecendo informações de cunho histórico cultural para a compreensão dos seus significados. (Mafro-Ufba, 2006, p. 02)

Conforme as diretrizes do documento oficial do museu, a ênfase da exposição permanente é na presença de elementos africanos que constituem as bases das culturas afro-brasileiras. Ao mesmo tempo que se busca produzir imagens alternativas aos estereótipos das presenças africanas nos cenários brasileiros, os acervos disponibilizam seus objetos para novas leituras, que sejam capazes de alçar os elementos históricos, étnicos e estéticos que constituem as dinâmicas identitárias entre as sociedades locais e os diferentes povos africanos que compõem o processo civilizatório brasileiro. Na relação com o Candomblé, o MAFRO-UFBA é um espaço profano, portanto a 'religiosidade' expõe apenas as dimensões historiográficas desta expressão da religiosidade afro-brasileira e não os seus preceitos sagrados, estes últimos resguardados às práticas religiosas que têm lugar nos terreiros das mais diferentes descendências que estão espalhados pela capital e interior do Estado da Bahia.

3. Utilizo aqui a noção de referência cultural indicada por Maria Cecília Londres Fonseca. A autora remete à ideia de que a "a expressão 'referência cultural' tem sido utilizada sobretudo em textos que têm como base uma concepção antropológica de cultura e que enfatizam a diversidade não só da produção material, como também dos sentidos e valores atribuídos pelos diferentes sujeitos a bens e práticas sociais". (Fonseca, 2000, p. 13) 
Para apresentação geral das análises neste artigo, utilizo os enunciados produzidos pelos 11 respondentes dos questionários. 0 meu objetivo é interpelar as narrativas ${ }^{4}$ produzidas sobre estranhamento etnográfico a partir da nossa visita ao MAFRO-UFBA no ano de 2013. Procuro situar os enunciados produzidos pelos estudantes no interior de descrições etnográficas (Laplantine, 2004) que auxiliem o estabelecimento de conexões entre o que foi dito e o que foi visto. Além de realizar o recurso verbal do texto descritivo, recorro ao uso de imagens fotográficas como textos não verbais que complementam o trabalho descritivo. A intenção destas orientações metodológicas é recompor os lugares de produção dos significados que geraram os resultados das análises aqui realizadas (Ricoeur, 2009). Ao lado das indicações teóricas mencionadas anteriormente vou adotar, também como referências de análises, as noções de 'processo civilizador' e 'configurações de sentido' segundo as contribuições de Norbert Elias (1994); as noções de 'ressonância' e 'formação de subjetividades individuais e coletivas', segundo acepção de José Reginaldo Santos Gonçalves (2005); e a noção de referências culturais proposta por Maria Cecília Londres Fonseca (2000).

Procuro destacar que as recorrências ao candomblé para justificativa dos estranhamentos resultam de um processo de longo prazo no qual as formas locais de socialização dos estudantes interditam esta religião afro-brasileira de seus horizontes de sentidos, apesar, paradoxalmente, da abundância de símbolos do candomblé no cotidiano da capital baiana. Ao mesmo tempo, os discursos sobre o estranhamento produzidos pelos estudantes oferecem configurações de sentidos que indicam possibilidades de uma compreensão mais substantiva do significado do estranhamento a partir de uma experiência de campo com fins didáticos. Compreendo que estes estudantes participam de redes de interdependência, nas quais se tornam produto/produtores de sentidos para suas experiências vividas (Elias, 1994, p.249). Ao mesmo tempo, as ambiências museais com os seus arranjos entre textos, imagens e objetos produzem discursos que ultrapassam as fronteiras que os dividem entre 'coisas sem vida' e 'coisas portadoras de almas' ${ }^{5}$, estabelecendo assim outras reverberações discursivas nas relações que tais coisas estabelecem com as pessoas que as 'visitam', afinal de contas “...os objetos que compõem um patrimônio precisam encontrar 'ressonância' junto a seu público” (Gonçalves,

4. Parto do pressuposto básico de que os enunciados destacados são atos discursivos que geram excedentes de significados (Ricoeur, 2009). A partir dos enunciados em destaque indicam-se as posições que os locutores ocupam na relação com as coisas observadas.

5. José Reginaldo Santos Gonçalves (2005) recorre ao conceito de fato social total de Marcel Mauss para afirmar que o patrimônio, em termos etnográficos, é portador de elementos materiais e imateriais de forma indissociável. Em outra obra (Gonçalves, Guimarães e Bitar, 2013), o autor recorre ao termo 'alma das coisas' para apresentar um conjunto de textos assinados por diferentes autores sobre a perspectiva dos patrimônios, materialidade e ressonância. 
2005, p.19). Sob efeito de tal ressonância, os estudantes participam de uma produção de sentido e valor (Fonseca, 2000, p.11) na qual também assumem o lugar de intérpretes do patrimônio cultural com que se relacionam.

As questões que orientam as análises são as seguintes: 1) Quais as narrativas produzidas sobre os estranhamentos etnográficos a partir das interações dos indivíduos com os objetos museais? Quais as configurações de sentidos dos estranhamentos produzidos por estas interações? Creio que seja importante ainda definir que tomo por referência a orientação de que "processo de estranhar o familiar torna-se possível quando somos capazes de confrontar intelectualmente, e mesmo emocionalmente, diferentes versões e interpretações existentes a respeito de fatos, situações [...]" (Velho, 2004, p.131). A experiência de campo proposta inscreveu o grupo no interior de um cenário que pertence às paisagens urbanas da cidade em que vivem e procurou correlacionar a noção de estranhamento a uma experiência pessoal passível de ser definida como 'estranhamento'. Após descrever os cenários, as narrativas produzidas e os objetos destacados, procuro apresentar um quadro geral sobre as principais configurações de sentido para os estranhamentos narrados.

\section{Cenários, objetos e narrativas do estranhamento}

O Museu Afro-Brasileiro da Universidade Federal da Bahia foi projetado no início da década de 1970 pelo Centro de Estudos Afro-Orientais da mesma universidade. Apesar de ser idealizado na década de 70 do século passado, o museu foi inaugurado apenas no ano de 1982. Está localizado no prédio da antiga Faculdade de Medicina da Bahia, à Praça do Terreiro de Jesus no Pelourinho. Além de estar situado no centro histórico da capital baiana, o museu ocupa as principais salas que ficam à entrada do prédio da antiga Faculdade, o que o coloca em uma posição politicamente relevante no interior de uma instituição que, ao longo da história, estabeleceu relações tensas e conflituosas com a presença do negro na sociedade local. Conforme lembra-nos Roger Sansi:

0 projeto do Museu Afro-Brasileiro chocou as elites mais velhas e conservadoras de discípulos de Nina Rodrigues, particularmente porque, segundo o projeto, o museu ocuparia o antigo prédio da Escola de Medicina no centro de Salvador. 0 professor de medicina Raymundo de Almeida Gouveia declarou que era uma ideia estranha e ruim colocar o Museu Afro-Brasileiro na 'primeira faculdade de Medicina Brasileira' [...] Esse penoso debate entre médicos e antropólogos culturais continuou até a abertura do Museu Afro-Brasileiro em 1980. (Sansi, 2013, p.114) 
Estes comentários nos oferecem uma noção dos conflitos que atravessam as 'paredes' do museu e que de certa forma são silenciados àqueles que se encantam pela exuberância das suas coleções, mas desconhecem as tramas políticas que fazem a história do lugar. As peças que compõem as exposições permanentes do museu estão distribuídas em 05 grandes salas. As duas primeiras salas são denominadas Setor Religiosidade Afro-Brasileira e Setor África. Após passarmos por estes setores, chegamos a duas salas que são dedicadas a exposições temporárias, estas duas salas oferecem vias de acesso ao subterrâneo do prédio onde está localizado o Museu Arqueológico e Etnológico da mesma Universidade e à quinta sala de exposição permanente em que encontramos grandes painéis de madeira esculpidos pelo artista plástico argentino Carybé.

A visita ocorreu no dia 07 de janeiro de 2013. Poucos dias após o retorno das festividades de final de ano. Em função da greve dos professores e funcionários da Universidade ocorrida no ano de 2012, tivemos um semestre 'atípico', planejei a visita ao museu para a retomada pós-festividades de final de ano, também como uma forma de manter o entusiasmo dos estudantes com os trabalhos que eu vinha desenvolvendo. Do conjunto de 21 estudantes, apenas 02 declararam já conhecer o Museu Afro-Brasileiro. Agendei a visita com muita antecedência, contudo neste dia não foi possível contar com a presença de um monitor para nos guiar; como eu já tinha algum domínio daquele espaço, conduzi a apresentação das salas com os seus objetos.

Dias depois desta visita, eu recebi os relatórios dos estudantes. Fiz uma leitura geral e percebi que a maioria dos objetos que provocaram estranhamento foi relacionada ao Candomblé pelos próprios estudantes, conforme mencionei no início deste ensaio. Dos 11 relatos produzidos 02 destacavam a Espada de Gu e outros 02 destacavam os Ibejis, objetos que fazem parte da exposição permanente do Setor África. Em seguida 02 pessoas demonstraram estranhar a escultura de Exu, que fica exposta entre o Setor África e as Salas de Exposições Temporárias. $\mathrm{Na}$ Sala Carybé 04 pessoas revelaram estranhar o painel em homenagem ao Orixá Ogum. Apenas 01 estudante revelou estranhar genericamente 'os objetos do candomblé que encontrou ao longo do caminho.

A título de maior sistematicidade na apresentação das narrativas dos estudantes, vou expor os seus enunciados a partir da descrição dos objetos tal como estão expostos no MAFRO-UFBA. A Espada de Gú (figura 01) é o símbolo do museu. Está afixada em um painel que faz a divisória interna do Setor África. A divisória é móvel e cria uma duplicação do Setor África com um corredor de texto e imagens diversas, que introduzem o visitante na diversidade cultural do continente africano. A Espada de Gu está afixada no lado posterior e ao centro do painel (no sentido de quem entra); ao seu lado constam fichas técnicas contendo 
informações sobre o pertencimento da espada ao Vodun (título equivalente ao de Orixál Gu e outros textos e imagens correlatas. Junto dela existe uma fotografia (assinada por Pierre Verger) da espada sendo sustentada por um membro de uma etnia africana: a imagem oferece uma visão da grandiosidade do objeto diante do homem que a sustenta. Há ainda uma escultura de Gu, textos e outros objetos alusivos à metalurgia. 0 objeto ocupa uma posição de destaque no conjunto geral do setor e está associado à escultura do Gu com a sua espada, compondo uma visão de conjunto entre a espada, o Vodum, a relação entre os humanos, o objeto e a divindade, pois, como foi dito anteriormente, é o objeto símbolo do museu. 0 objeto foi feito em metal no Benin pelo escultor Simon Akati; próximo a ele consta um texto sobre a forja do ferro. A principal mensagem do painel é sobre a produção da metalurgia em África; o texto central, aposto em uma das extremidades do painel, destaca o seguinte: A Tecnologia da Fundição de Metais - Descrição do Processo da 'Cera Perdida'. As narrativas que apresentam a Espada de Gu como objeto que provocou o estranhamento dizem o seguinte:

[...] Era uma ferramenta utilizada por um grande guerreiro e desbravador para abrir o caminho e derrotar os inimigos. Gu era uma divindade do Povo Fon do Reino do Daomé, atual República Popular do Benin [...]" (ESTUDANTE 1) [...]. Devido a seus detalhes incrivelmente significativos e sua estatura que remete à grandiosidade da divindade que a impunha [...] passei boa parte observando,e, a cada momento, percebia um detalhe novo [...] (Estudante 2)

Figura 01

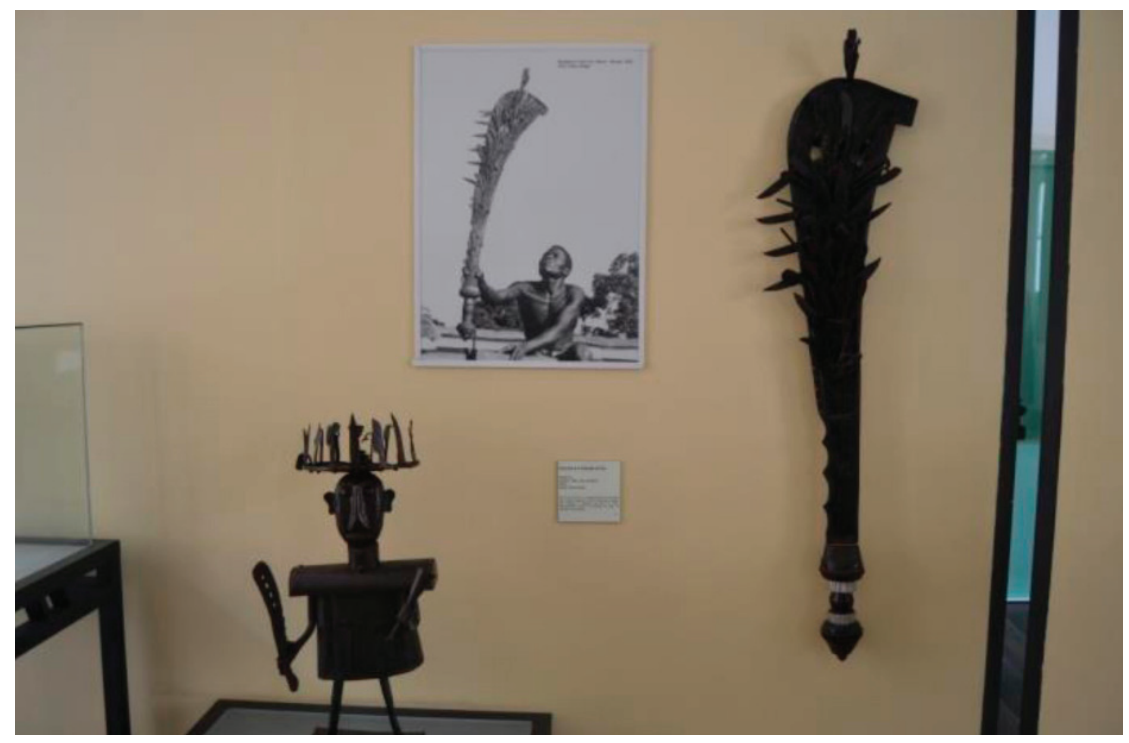

Fotografia do Autor - Espada de Gu (à direita) 
A primeira narrativa faz uma reelaboração do texto que compõe a ficha de informação afixada ao lado da Espada; de certa forma a perplexidade se dá pela descoberta de um objeto que até então era desconhecido para a estudante. A segunda estudante enfatiza a sua perplexidade diante da beleza do objeto.

Outros dois objetos presentes no mesmo Setor África que foram alvos de estranhamentos por parte dos estudantes foram estatuetas de gêmeos (figura 02), que foram relacionadas com os orixás Ibejis.

Figura 02

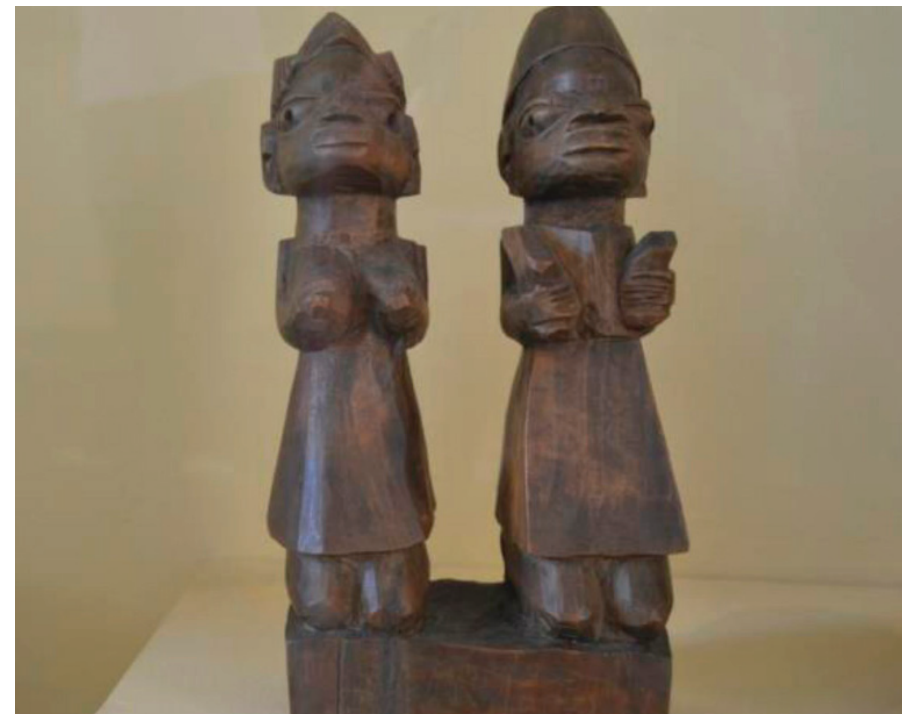

Fotografia do Autor - IBEJIS expostos no MAFRO

Há dois conjuntos de esculturas com os gêmeos masculino-feminino, ambas estão situadas em duas vitrines do Setor África. A primeira vitrine está afixada à parede que faz a divisória com o Setor Religiosidade Afro-brasileira, próximo a uma janela que oferece uma vista do Terreiro de Jesus no Pelourinho. É a terceira le últimal vitrine deste local para quem está iniciando a vista pelo acesso principal do MAFRO. Nesta vitrine estão duas pequenas esculturas feitas em gesso, que, segundo a ficha de informação exposta, são réplicas de esculturas da etnia Luba da República Democrática do Congo. As réplicas são originárias de peças do acervo do Museu Real da África Central, localizado em Tervuren, na Bélgica. A segunda peça dos gêmeos está situada no interior da única e principal vitrine, que fica no salão central do Setor África. A vitrine constitui o maior móvel do local; ela está afixada ao lado de plataformas de madeira que dão relevo às máscaras Geledés do museu. Trata-se de uma peça única originária da Nigéria, pertencente à etnia lorubá 
e esculpida em madeira por Olá Ogum. Os destaques dados a estas peças foram os seguintes:

Quando visualizei a imagem de São Cosme e Damião, fiquei um pouco assustada porque com o meu olhar leigo imaginava que os santos fossem dois meninos, mas 0 que estava sendo mostrado na imagem era um menino e uma menina [...] (Estudante 3) [...] 0 estranhamento foi perceber traços na cultura africana de que o homem pode ter qualidades/personalidades femininas. Como exemplo deste estranhamento foi a imagem dos IBEJIS [...] um dos meninos tinha traços femininos como 'tetas' [...] (Estudante 4)

Nestes dois relatos, ocorre a recorrência 'ao desconhecimento' como fator de estranhamento no relato da Estudante 3. Na tentativa de estabelecer referências entre aquilo que vê e aquilo que já conhece a respeito do que é visto, a estudante remete a imagem dos gêmeos aos santos católicos Cosme e Damião, o que sugere um apagamento histórico das referências ao candomblé por efeito do sincretismo religioso com o catolicismo, por meio do qual se instituíram práticas amplamente difundidas de correlações entre os 'santos católicos' produzidos pela Europa e os 'orixás africanos'. No relato da Estudante 4, o destaque recai nas diferenças de representações de gênero por meio das marcas do feminino e do masculino nos corpos dos gêmeos.

Outra peça que foi alvo de 02 observações de estranhamento foi a imagem de Exu (figura 03). Logo após a nossa visita, esta entidade foi colocada em evidência com uma exposição temporária intitulada: Exu: outras faces.

Figura 03

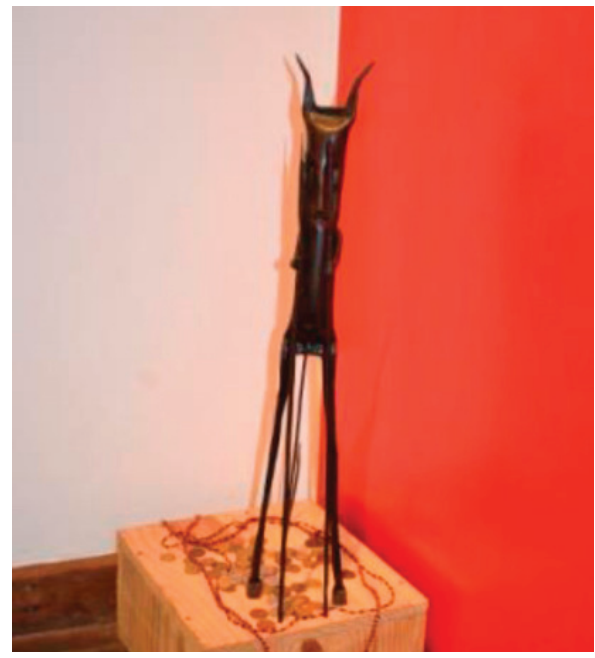

Fotografia do Autor - Exu 
A imagem está afixada no canto entre as salas do Setor África e a exposição temporária. A localização do objeto indica um 'estar à espreita'. É uma imagem pequena feita em metal. Está posta sobre um altar feito de caixote de madeira, no qual constam guias de contas referentes ao Orixá e oferendas de moedas. Para a exposição, foi feita uma cortina de fitas de cetim preto e vermelho (cores do orixál. Esta cortina faz uma divisória entre o Setor África e a exposição temporária; é uma peça de muita leveza que dá o testemunho de o vento abrindo a passagem dos visitantes. A partir do local em que está a imagem principal de Exu, é possível ver em perspectiva a relação entre os diferentes espaços do museu e a via de acesso principal ao subsolo, onde encontra-se o Museu Arqueológico e Etnológico. É a composição da encruzilhada, local de passagem dos quatro ventos, posição que permite uma visão de múltiplos ângulos. A sala se desdobra em várias imagens alusivas a Exu. Os relatos das estudantes diante da imagem principal do Exu foram os seguintes:

0 Exu. Por não conhecer a sua cultura, à primeira vista choca um pouco. Quando vemos o desconhecido, sem entender a sua história e tradições, tendemos no primeiro momento a criticar, mesmo que sem base ou fundamentos [...] (Estudante 5) [...] 0 Exu tem a sua virilidade exuberante voltada para a terra, representando a fertilidade do solo, poder e tradições. Isto provocou estranhamento em virtude de ter aprendido um valor atribuído ao diabo [...] (Estudante 6)

Além de colocarem destaque para o desconhecimento das representações do Exu nos rituais do Candomblé, uma das estudantes enfatiza a 'virilidade' do Orixá; aliás este é um dos aspectos que costuma provocar 'bochichos' nas nossas visitas: a imagem do Exu enfatiza o 'falo' como símbolo de fecundidade, sensualidade e poder.

0 maior número de relatos, no entanto, remete à escultura de Ogum, nos painéis de Carybé (figura 04).

Figura 04

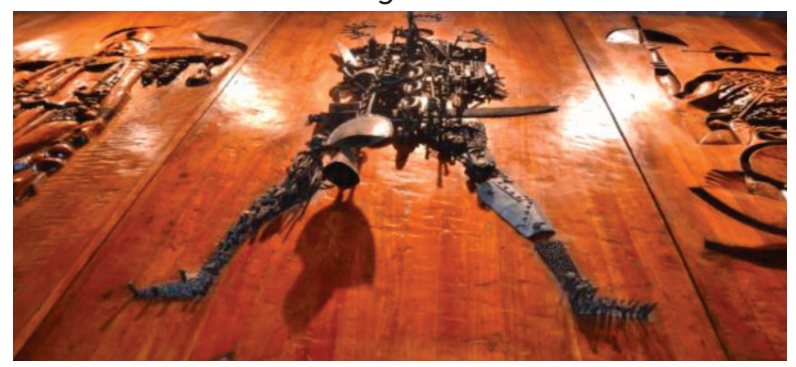

Fotografia do Autor - OGUM do Painel Carybé 
A imagem está no painel esculpido por Carybé e oferecido ao MAFROUFBA. Destaca-se pela afixação de várias peças de metal no corpo do orixá, simbolizando a sua relação com a tecnologia e a metalurgia. A imagem de Ogum está na lateral direita que dá sequência à porta de entrada. É a terceira placa de madeira no sentido ascendente de quem entra à sala. Além da monumentalidade da sua apresentação no conjunto da obra, é uma das imagens predominantes no painel, graças à presença dos metais no corpo do orixá. Há nesta sala um pôster com informações sobre os orixás e suas principais características, bem como um pôster sobre o artista e o processo de produção dos painéis. Além disto, há outro pôster com imagens diversas de aquarelas de Carybé retiradas do livro: "Inconografia dos Deuses Africano no Candomblé da Bahia”. A propósito do painel de Ogum os relatos foram os seguintes:

A imagem de Ogum, pois ele possui ferros em seu corpo, é cheio de metais, como se representasse uma pessoa 'carregada' de algo ruim [...] a imagem é forte [...] (Estudante 6); "Logo quando entrei na sala tomei um susto, assim que olhei para o painel desse Orixá, Ogum, com o meu olhar pensei que fosse um Orixá maligno [...] Aquilo me causou estranhamento, foi algo totalmente diferente da minha cultura cristã, na minha crença as imagens são serenas [...]" (Estudante 7); " 0 painel dos Orixás, pois tive um impacto visual muito forte [...] trata-se de uma cultura desconhecida para mim [...]" (Estudante 8); "0 ambiente é fora dos padrões para mim [...] Fiquei impressionada com a riqueza dos detalhes e com a relação entre os Orixás e os animais, sobretudo Ogum, que está relacionado com um cachorro" (Estudante 9); Fiquei impressionada com a 'carga' de correntes, facas e espadas em Ogum, além de achar bonito, achei forte também (Estudante 10).

Além da ênfase nos aspectos estéticos e no desconhecimento acerca dos elementos simbólicos que estão presentes na representação do Orixá, surgem enunciados que revelam uma situação de confronto ideológico entre a cultura cristã e o Candomblé. Aliás, este aspecto está marcado no único destaque que foi dado ao Candomblé como 'fato' que produziu estranhamento em uma das estudantes:

Os objetos que me provocaram estranhamento foram algumas imagens, instrumentos e símbolos do Candomblé. Posso dizer que causou estranhamento porque, pelo grupo social com que convivi, adquiri preconceitos durante o processo de construção da minha identidade pessoal; confesso que respeito diferenças, porém tenho bloqueio em relação a algumas culturas, consequência da forma de construção de meu ver, diante da cultura do outro [...] (Estudante 11) 
Este relato coloca em evidência o confronto entre visões de mundo como uma emergência das relações estabelecidas entre a estudante e as 'coisas' expostas no museu. Há um efeito metonímico entre o recurso da referência ao Candomblé e os objetos expostos. A remissão ao Candomblé como fenômeno religioso é apenas uma pequena parte da exposição permanente que produz um efeito totalizador nas configurações de sentido desta estudante. Tal efeito traduz, de certa forma, as ações de longa duração de um processo civilizador com ênfase numa 'cultura cristã'; podemos concordar com Norbert Elias (1994, p.247) quando o autor nos faz entender que “ [...] no curso deste processo, muda a estrutura dos seres humanos, que se tornam 'mais civilizados'[...]". No entanto, ainda segundo as pistas deste mesmo autor, quando redescobrimos os seres humanos como seres abertos e transpassados por diferentes redes de interdependências, encontraremos também as tensões que promovem mudanças individuais e coletivas. Ao mesmo tempo, as relações entre as pessoas e os patrimônios são constituídas por processos de formação de subjetividades individuais e coletivas, “[...] os patrimônios podem assim exercer uma mediação entre os aspectos da cultura classificados como 'herdados' por uma determinada coletividade humana e aqueles considerados como 'adquiridos' ou 'reconstruídos'[...]". (Gonçalves, 2005, p.28)

0 Museu Afro-Brasileiro da UFBA é também um campo de disputas, um lugar em que intelectuais e representações dos movimentos sociais reivindicam o reconhecimento das relações de pertencimento afro-brasileiras que estão presentes na formação das sociedades locais e nacionais, mas, também, um lugar que alguns representantes da Faculdade de Medicina reivindicam, a título de demarcação dos pertencimentos com as heranças coloniais do ocidente na Bahia. A manutenção do Museu tem permitido a construção de novas relações com a sociedade local e favorecido o desenvolvimento de práticas educativas capazes de recompor os sentidos dos processos civilizacionais na contemporaneidade.

\section{Configurações de sentidos, referências culturais e recorrências discursivas}

O MAFRO-UFBA reúne objetos, histórias e um complexo tecido de relações sociais que constituem importantes 'acervos' e 'tensões' do patrimônio cultural baiano e nacional. Os estranhamentos destacados foram produzidos a partir diferentes posições dos arranjos entre objetos, textos, imagens e demarcações espaciais que orientaram os estudantes ao longo da visita. As configurações de sentido, além de apresentarem alguns 'nexos' das relações de interdependência (Elias, 1994) entre as 'coisas' e 'fatos' observados e aqueles que os observavam, 
possibilitaram também a 'apropriação de sentidos' segundo as referências culturais (Fonseca, 2000) emergentes de suas narrativas. É importante assinalar que os enunciados produzidos para caracterização do estranhamento indicam, em termos gerais, o recurso a referências culturais que circulam socialmente no interior dos contextos de vida dos estudantes. 0 grupo, em geral, preferiu utilizar suas experiências de vida na composição de narrativas, em lugar de expor conceitos ou noções teóricas trabalhadas previamente em sala de aula.

0 quadro geral a seguir expõe uma sinopse dos resultados provisórios desta breve análise. A primeira coluna destaca principais temas que atravessam as configurações de sentido produzidas. Em seguida estes temas se desdobram em referências culturais mediante as quais as relações entre os estudantes e as coisas observadas "falam daquele contexto cultural no sentido de representálo" (Fonseca, 2000, p.14). 0 número de recorrências destaca a frequência com que configurações de sentido e referências culturais aparecem ao longo das narrativas.

Quadro geral

Configurações de sentidos e desdobramentos das

narrativas sobre o estranhamento

\begin{tabular}{|c|c|c|}
\hline $\begin{array}{c}\text { Configurações de } \\
\text { sentidos }\end{array}$ & Referências culturais & $\begin{array}{c}\text { Número de } \\
\text { recorrências }\end{array}$ \\
\hline Estéticas & $\begin{array}{r}\text { Remetem aos aspectos ligados às } \\
\text { formas, beleza e à arte presentes } \\
\text { nos objetos. }\end{array}$ & 03 \\
\hline Ideológicas & $\begin{array}{c}\text { Remetem aos confrontos de } \\
\text { visões de mundo, sobretudo às } \\
\text { diferenças religiosas ou a aspec- } \\
\text { tos míticos ligados aos objetos. }\end{array}$ & $04^{1}$ \\
\hline Diferenças de gênero e \\
sexualidade & $\begin{array}{c}\text { Destacam aspectos antropomór- } \\
\text { ficos que definem as diferenças } \\
\text { de gênero ou remetem a aspec- } \\
\text { tos da sexualidade. }\end{array}$ & $05^{2}$ \\
\hline Agnosiológicas & $\begin{array}{c}\text { Remetem à ausência de qualquer } \\
\text { fonte prévia de conhecimento } \\
\text { sobre o objeto observado. }\end{array}$ \\
\hline
\end{tabular}

Elaboração do Autor: ${ }^{1}$ Indicam dupla recorrência das configurações de Exu, ${ }^{2}$ Indicam a dupla recorrência dos Ibejis. 
Em termos gerais, as recorrências discursivas apresentam um relativo equilíbrio temático e de atribuição referencial às configurações de sentido expostas. 0 que eu pretendi indicar foi que enquanto as configurações de sentido apresentam nexos gerais dos estranhamentos, as referências culturais devem ser compreendidas como desdobramentos nocionais destas configurações que expõem as significações presentes nas narrativas dos estudantes. Destaquei a variação de recorrências entre as configurações e referências atribuídas a Exu a título de enfatizar que algumas narrativas não se deixam aprisionar por uma 'visão fechada' do objeto, além de extrapolarem um sentido único elas expõem as ambiguidades que são próprias das relações estabelecidas.

É importante destacar que, ao longo da experiência, foi possível problematizar as configurações de sentidos produzidas pelos estudantes a partir dos conteúdos da antropologia da educação trabalhados em sala de aula. Apesar de as respostas terem recorrido às experiências de cada um dos estudantes, o uso posterior de conceitos tais como estranhamento etnográfico, alteridade e etnocentrismo lestes dois últimos resultantes das discussões sobre a experiência etnográfica propriamente dital contribuíram significativamente para a extrapolação das expressões de senso comum que ainda distorcem as diferentes presenças da África nas relações históricas com o Brasil. Neste sentido, além da destacada importância dos acervos e agentes museais e dos processos pedagógicos por eles protagonizados, a atuação de educadores que procuram estabelecer interlocuções entre tais acervos e agentes, por meio dos seus conteúdos e práticas de ensino, é de fundamental importância para ampliar a compreensão do que é visto e vivido ao longo de uma experiência de campo com finalidade educativa. A partir de um projeto didático em campo, é possível alçar outras formas de produção de conhecimento em sala de aula, ao mesmo tempo que são proporcionadas outras compreensões das proximidades entre teorias e práticas nos processos formativos.

\section{Conclusões}

Suponho que as análises aqui apresentadas contribuem para as reflexões que levam em conta as relações entre aprendizagem e processos formativos em espaços não escolares. Destaquei um museu antropológico como um lugar de formação que contribui para os trabalhos de mediação e articulação das referências culturais locais e os processos de patrimonialização da cultura. 0 que eu pretendi, também, até aqui foi indicar que, além da necessária produção intelectual, sobretudo por meio da pesquisa antropológica, o ensino 
da antropologia pode oferecer importantes ferramentas para os processos de patrimonialização da cultura. Procurei desenvolver, ainda que de maneira provisória, uma noção de intencionalidade pedagógica articulada ao projeto antropológico a partir das contribuições de Franz Boas, Regina Abreu e Carlos Rodrigues Brandão. Em seguida descrevi em linhas gerais uma experiência didática em campo como base empírica para as análises. Recorri a Norbert Elias, Maria Cecília Londres Fonseca e José Reginaldo Santos Gonçalves para sistematizar, de maneira ampla, a importante produção de sentidos que decorreu desta experiência.

A título de último esclarecimento, devo dizer que as análises propostas neste artigo tentam dar relevo a um nível de produção de sentidos nos processos de patrimonialização que não é, exclusivamente, aquele que está ligado aos indivíduos que produzem artefatos culturais ou que são eles mesmos 'entidades patrimonializáveis', sobretudo artesãos ou praticantes de ofícios ligados às formas institucionalizadas de patrimônio cultural no Brasil. Há um nível de mediação e articulação nos processos de patrimonialização que passam por outras redes de socialização; no caso particular deste texto, as redes sociais constituídas em ambientes educacionais. Penso que procurei indicar o importante papel que as instituições educacionais podem ocupar não apenas nos processos de patrimonialização, mas, também, nos processos civilizadores contemporâneos. Compartilho com os autores escolhidos para a composição deste texto de que a matéria prima e a alma que compõem os patrimônios culturais são produzidas pela humanidade que nos constitui e que também passa por dentro de nossas escolas.

\section{Referências}

ABREU, R. Patrimônio Cultural: tensões e disputas no contexto de uma nova ordem discursiva. In: LIMA FILHO, M. F.; ECKERT, C.; BELTRÃO, J. F. (Org). Antropologia e patrimônio cultural diálogos e desafios contemporâneos. Blumenau: Nova Letra, 2007.

BOAS, F. A formação da antropologia americana: 1983-1911. Rio de Janeiro: CONTRAPONTO, Editora UFRJ, 2004.

BRANDÃO, C. R. A educação como cultura. São Paulo: Editora Brasiliense, 1986. ELIAS, N. O processo civilizador: uma história dos costumes, vol 1. Rio de Janeiro: Jorge Zahar Editor, 1994.

FONSECA, M. C. L.. Referências culturais: base para novas políticas de patrimônio. Em: Manual de Aplicação do INRC. Brasília, Iphan/DID, 2000, pp. 11-21. 
GONÇALVES, J. R. S.; GUIMARÃES, R. S.; BITAR, N. P. (Org). A alma das coisas: patrimônios, materialidade e ressonância. Rio de Janeiro: Mauad X : FAPERJ, 2013.

GONÇALVES, J. R. S. Ressonância, materialidade e subjetividade: as culturas como patrimônios. Horizontes Antropológicos, vol 11, n. 23, Porto Alegre, ano 11, n. 23, 2005, pp. 15-36.

HORTA, Maria de Lourdes Parreiras. Lições das coisas: o enigma e o desafio da educação patrimonial. Revista do Patrimônio Histórico e Artístico Nacional,n. 31, Brasília, Iphan, 2005, pp. 220-233.

LAPLANTINE, F. A descrição etnográfica. São Paulo: Terceira Margem, 2004.

RICOEUR, P. Teoria da interpretação: o discurso e o excesso de significação. Lisboa: Edições 70, 2009.

SANSI, R. A vida oculta das pedras: historicidade e materialidade dos objetos do candomblé. In: GONÇALVES, J. R. S.; GUIMARÃES, R. S.; BITAR, N. P.; (Org). A alma das coisas: patrimônios, materialidade e ressonância. Rio de Janeiro: Mauad X : FAPERJ, 2013.

UNIVERSIDADE, Federal da Bahia. Setor religiosidade afro-brasileira: projeto de atuação pedagógica e capacitação de jovens monitores. Salvador: MAFROCEAO-UFBA, 2006.

VELHO, G. Individualismo e cultura: notas para uma antropologia da sociedade contemporânea. Jorge Zahar Editor: Rio de Janeiro, 2004.

Recebido em junho de 2014

Aprovado novembro de 2014

Álamo Pimentel é doutor em educação pela Universidade Federal do Rio Grande do Sul (UFRGS), professor da Universidade Federal de Alagoas (UFAL) e colaborador no Programa de Pós-Graduação em Educação da Universidade Federal da Bahia (UFBA). E-mail: alamopimentelmczlagmail.com 